\title{
Supplier Satisfaction as a Mediating Effect on Delivery and Service: A PLS-SEM Approach in India During COVID-19 Pandemic
}

\author{
Trishit Banerjee $^{1}$ (D)
}

Received: 1 August 2021 / Accepted: 6 January 2022 / Published online: 16 February 2022

(c) The Author(s), under exclusive licence to Springer Nature Singapore Pte Ltd 2022

\begin{abstract}
Purpose The role of suppliers is emerging to be of considerable importance given the current state of competition in times of globalization and technological advancements. Past studies have depicted considerable importance in determining supplier satisfaction for generating client satisfaction. The purpose of this article is to investigate the role that Supplier Satisfaction (SS) plays in partnering with manufacturers and traders in connection with the SME in India during the difficult COVID-19 era of business and to propose and demonstrate these collaborations.

Methods I present a partial least-squares structural equation model. Production units and manufacturers are attracted to the satisfaction of both distributors as well as distributors, leading to B2B loyalty.

Results This paper supports the idea that the benefits derived from the relationship between the four explanatory points of the solution are a significant extension of the first type. Ironically, the response to corporate policies and regulations has declined dramatically. This decision was surprising, because a strong communication strategy had already affected the image of the service provider.

Conclusion To be sure, the experiment has a system in place to update the performance of these suppliers by examining the effect of supplier certification on supplier verification and engagement.
\end{abstract}

Keywords PLS-SEM - Supplier Satisfaction $\cdot$ B2B loyalty $\cdot$ SME

\section{Introduction}

Research in supplier satisfaction and the favoured client proposal take the perspective of clients contending for competent providers among supply administration researchers. The most vital reason is the organizations, particularly in developed markets, and lessens their supply base to get benefits. Also, because of expanded outsourcing of non-centre exercises and open advancement activities, purchasing firms are progressively reliant on their providers. In this manner, researchers contend that purchasers should see the provider as a key source of advancement and attempt to accomplish

This article is part of the topical collection "Intelligent Systems" guest edited by Geetha Ganesan, Lalit Garg, Renu Dhir, Vijay Kumar and Manik Sharma.

Trishit Banerjee

trishit.banerjee@nsec.ac.in

1 Department of Basic Engineering and Science, Netaji Subhash Engineering College, Kolkata, India privileged client status [7]. Especially during the COVID-19 times, due to restrictions imposed, there have been significant barriers faced by purchasers along with suppliers that deterred the final delivery of goods. While multiple businesses were able to mobilize rapidly by forming nerve centre that enabled them to build resilience. The current scope of research applies the PLS-SEM model to determine the satisfaction of suppliers in an Indian real-estate company, such that they ensure delivery of products and services efficiently during the COVID-19 pandemic.

\section{Primary Objective}

The primary aim of the scholar was to classify the factors of supplier satisfaction to assure the obligation of the suppliers towards the distribution of superior products and efficient service. The theoretical model has been designed based on the theory of Planned Behaviour. A real-estate company based in India that was responsible for developing business office spaces was selected for the study and data from suppliers were collected via-Supplier portal. Among the 
strength of 2900 suppliers of the company, questionnaires were sent to suppliers, and response from 136 suppliers was received. The scholar finally analyzed the response of 72 valid responses from the suppliers.

\section{Theoretical Model}

The behavioural responses of the suppliers were arbitrated by three different contemplating factors; normative expectations, beliefs about behaviour, and control beliefs. The four peripheral aspects, which were affecting the obligation of the suppliers for providing quality service as per the TQM model, were purchase policies, coordination, corporate image, and payment policies. The research model has been depicted in (Fig. 1) following a well-constructed planned behaviour model [2].

\section{Mathematic Model}

\section{Hypotheses and Variables}

The following hypotheses were investigated through partial least square structured equation modelling.

H1. Acquiring arrangement taken by the company has a positive effect on satisfying supplier responsibility.

$\mathrm{H} 2$. Buying strategy taken by the company has a positive impact on the corporate image.

H3. Expense and budgetary of the organization have a positive impact on satisfying supplier duty.
H4. Imbursement and money-related decisions taken by the organization have a positive effect on corporate image.

H5. Imbursement and money-related decisions taken by the organization have a positive effect on coordination strategy.

H6. Coordination strategy taken by the company has a positive effect on satisfying supplier duty.

H7. The coordination strategy taken by the company has a positive effect on acquiring strategies.

H8. The coordination strategy taken by the company has a positive effect on corporate image.

H9. The corporate image of the company has a positive effect on satisfying supplier duty.

H10. Satisfied Supplier responsibility positively affects the delivery of products and ventures according to the TQM model.

The factors of the study were assemblage through exploratory factor analysis. The mediator variable was observed as the satisfaction of the suppliers, and the independent factors were purchase policy, coordination strategy, payment method, and corporate image. The factor depending on the independent factors was the effective delivery of commodities and services catered by the suppliers.

\section{Descriptive Assessment of Sample Data}

The supplier data were demographically analyzed for age, nationality, gender, level of education, company size, and years of association with the company based in India.

\begin{tabular}{|c|c|c|}
\hline Rational Policies Aspects & Supplier Intention & Supplier Behavior \\
\hline
\end{tabular}

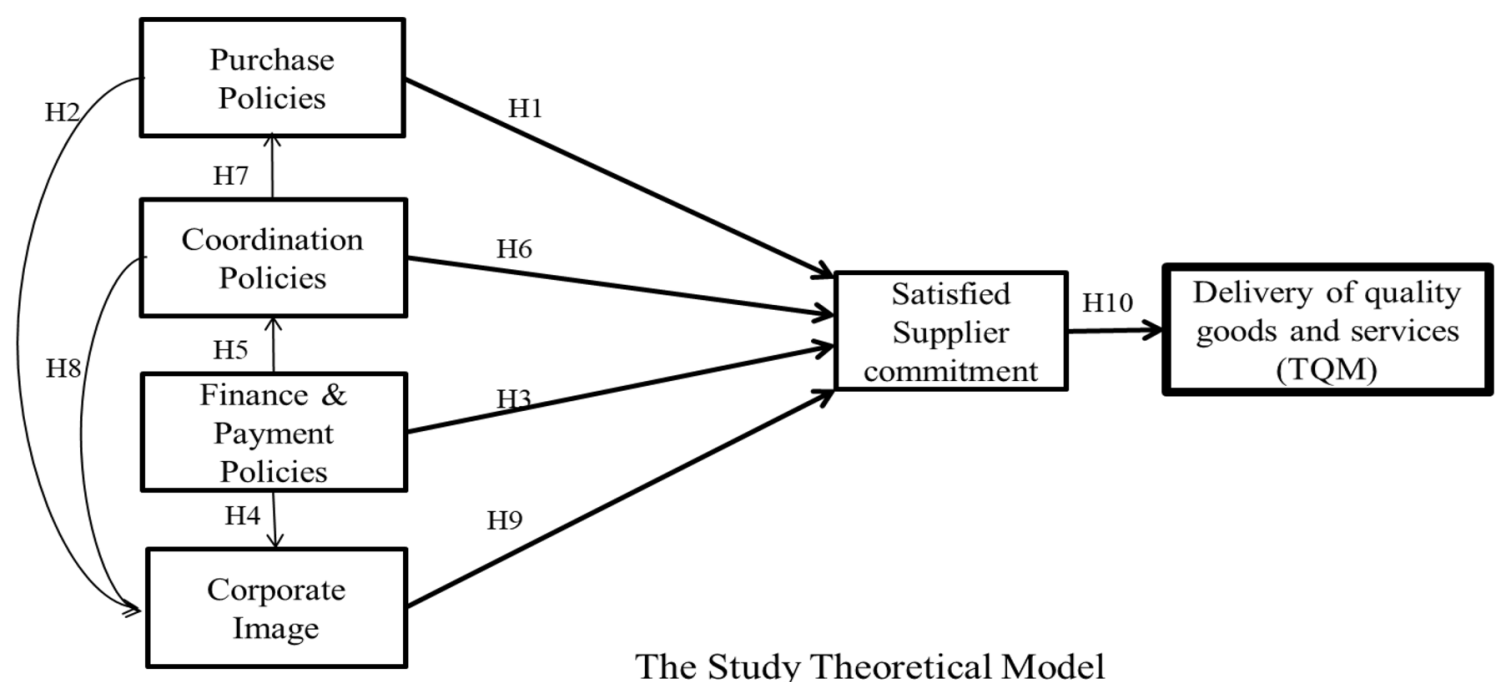

Fig. 1 Theoretical model of the current study 
1) What is your gender?

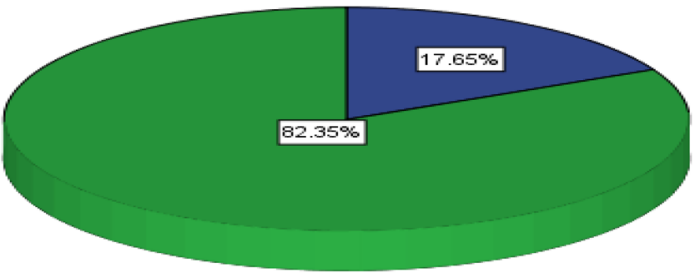

Fig. 2 Gender distribution of the suppliers

The response was received from 24 female (17.65\%) and 112 male distributors ( $82.35 \%)$, and the dominance of male distributors was prominent (Fig. 2).

The nationality scrutiny revealed that the majority of the suppliers were either from India $(N=35,25.74 \%)$ and UAE $(N=25,18.38 \%)$. Pakistan $(N=20,14.71 \%)$ and Egypt $(N=21,15.44 \%)$ also contributed bulk of the suppliers. It was easily comprehensible that most of the suppliers were either from the Asian or African continent (Fig. 3).

Most of the suppliers were in the age bracket of $30-49$ years $(N=94,69.1 \%)$, whereas a number of suppliers from 65 years and above were the least $(N=3,2.21 \%)$.
The age distribution reflected the validity of the responses, as mature responses were expected from a distributor aged 30 years or more (Fig. 4 ).

Qualification of the suppliers reflected that most of them had bachelor degrees $(N=76,55.88 \%)$ followed by high school degrees $(N=33,24.26 \%)$. Only 19 (13.97\%) had some kind of technical or vocational training (Fig. 5).

A huge section of the purveyors had both small $(N=45$, $33.09 \%)$ and medium $(N=53,38.97 \%)$ enterprises. Thus, it was vastly probable that the commitment of the contented supplier for offering remarkable service and delivery towards the company was quite credible (Fig. 6).

A large fraction of the suppliers $(N=54,39.71 \%)$ were connected with the company for over 5 years (Fig. 7). In addition, there were a brand-new group of dealers, too, available out there who were involved in working with the company for the last $2-3$ years $(N=35,25.74 \%)$.

\section{Quality Appraisal of Data-Based Factors and Structure}

A thorough investigation of the 73 response-related data was performed through PCA or Principal Component Analysis. The Varimax rotation and orthogonal rotation (default) were employed during the PCA during the assessment of
Fig. 3 Nationality of the suppliers

\section{2) Nationality:}

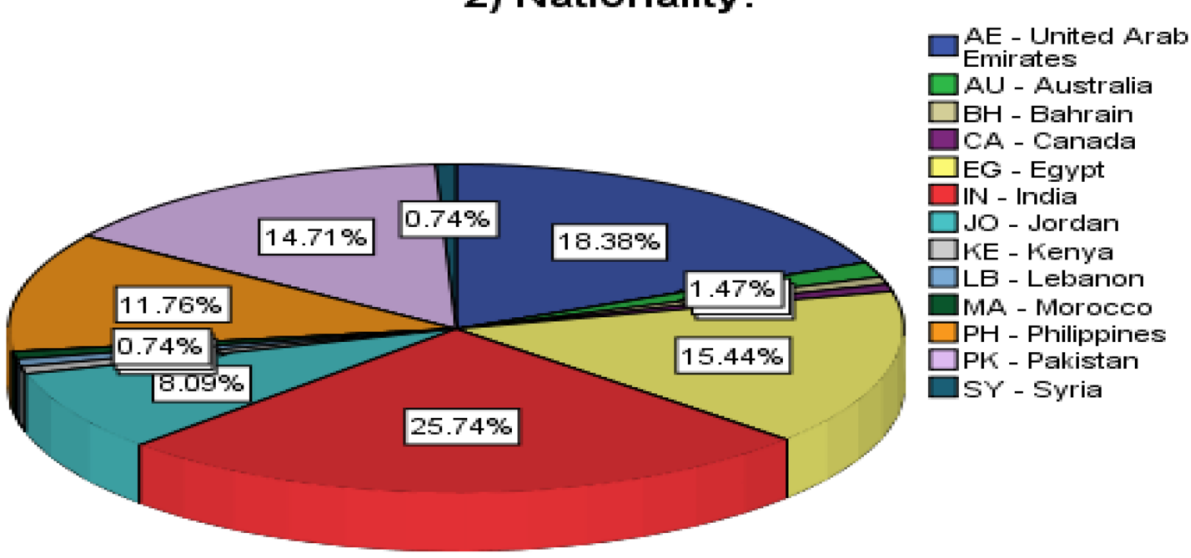

3) What is your age?

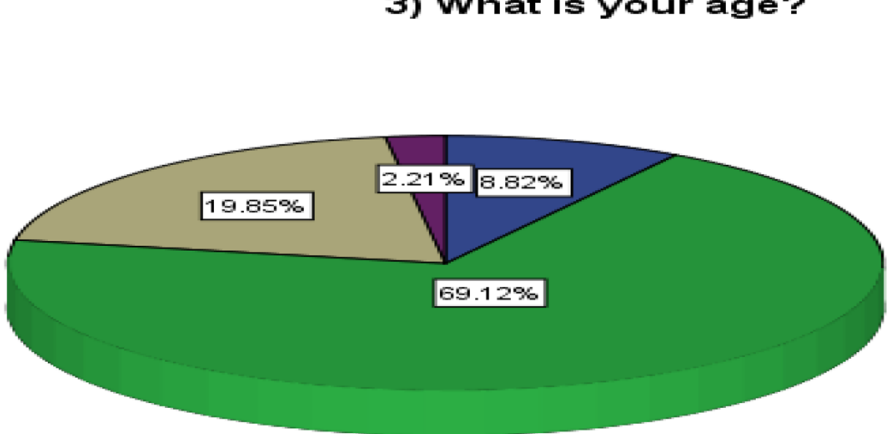

Fig. 4 Age distribution of the suppliers 
Fig. 5 Education level of the suppliers
4) What is the highest level of education you have completed?

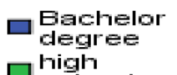

$\square$ high

school

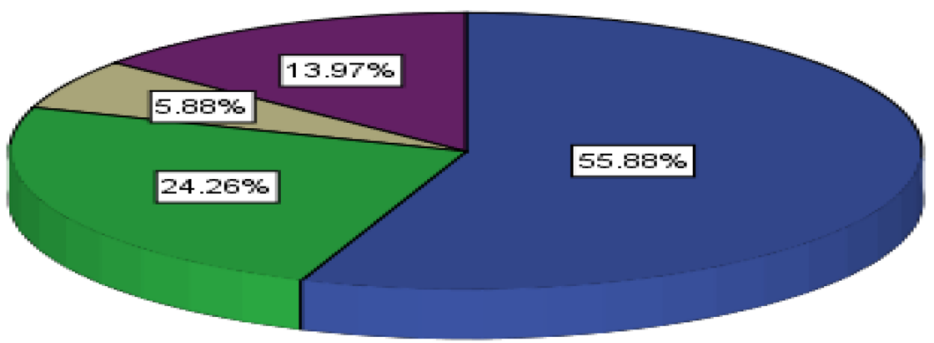

5) What is your company size category:

Fig. 6 Company size of the distributors

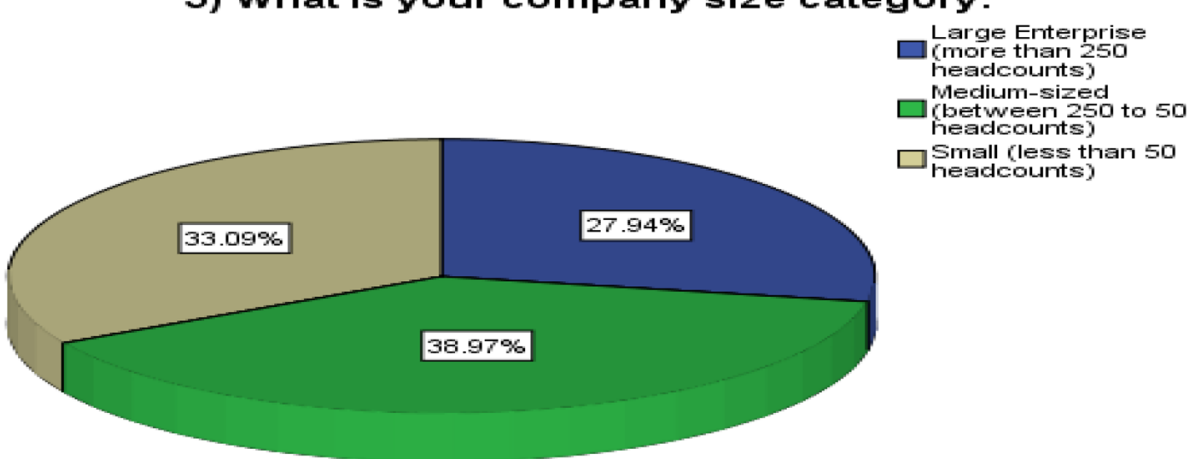

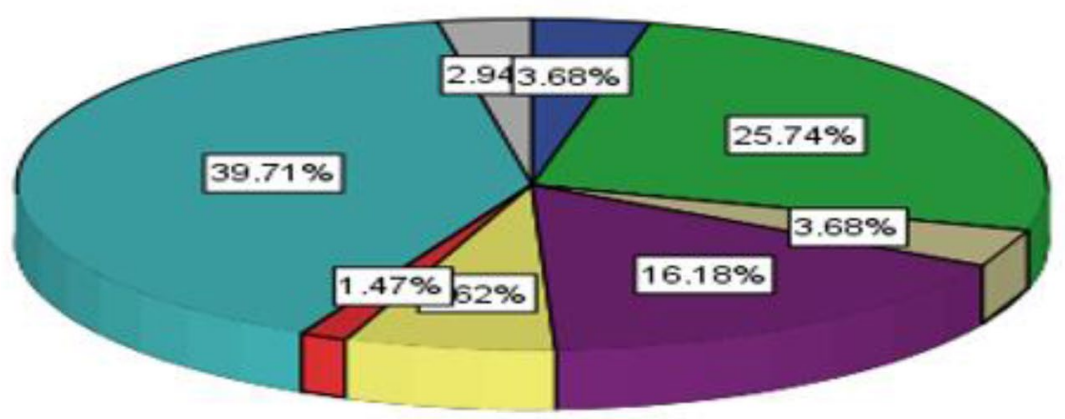

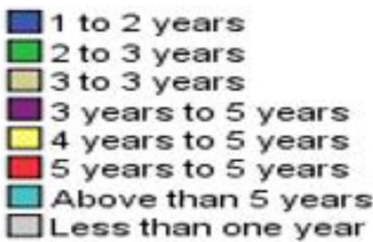

Fig. 7 Level of association with the company

the factor loadings. It, in turn, helped the module in retaining 31 additional factors. The segregation standard was the lowest cut-off loading of around 0.4. The aspects were classified under six different modules, which are corporate image, payment policies and purchase policies, coordination, performance by TQM standards, and supplier satisfaction. The exploratory factor analysis (EFA) was authenticated by Bartlett's test of Sphericity $(\mathrm{BT}=2299.64, p<0.05)$ and Kaiser-Meyer-Olkin test $(\mathrm{KMO}=0.83, p<0.05)$. The factors, which had a loading of over 0.6 , were ultimately measured to be noteworthy for creating the six different modules of the whole research. The SPSS software platform was employed for scrutinizing the factors and exported again to excel for simplifying the latent factors alongside their components. The dependability of these factors (of purchase policy) was, later, measured, and the resulting Cronbach's Alpha was premeditated as 0.90 . The modules of synchronization policy seemed to be very consistent with Cronbach's Alpha 
of around 0.91. The same level of consistency was revealed among the components of the corporate image $(\alpha=0.88)$, payment policies $(\alpha=0.86)$, delivery policies as per the TQM $(\alpha=0.91)$, and supplier satisfaction $(\alpha=0.91)$. The inner reliability of the factors had depicted the legitimacy of the well-thought-out EFA model. The above-mentioned calculations were made based on the assumption of equal error variances and equivalent factor loadings [4] (Table 1).

Also, a supplementary evaluation of the factor-based distinctiveness was performed with regards to compound dependability for construct consistency of the heterogeneous model. These calculations incorporated the latent factor scores of all items calculated in SMARTPLS 3.0 and exported back to SPSS. It was observed that composite reliability and internal reliability measures were very close to each other. The average variance extracted (AVE) for the latent factors were greater than 0.5 , which indicated the convergent validity of the partial least square (PLS) model. The latent constructs of the PLS model were concluded to be correlated from the values of alpha and AVE. The PLS model has been provided in tabular structure in Fig. 9 (Table 2).

\section{Initial PLS-SEM Model}

The initial model (Fig. 8) explained that payment policy, purchase policy, and coordination policy predict the corporate image of the suppliers, whereas all four independent factors affect supplier satisfaction. Supplier satisfaction acts as a mediating variable, which eventually predicts the quality of delivery of products and services in accordance with the
Table 1 Factor loading from EFA (exploratory factor analysis)

\begin{tabular}{|c|c|c|c|c|c|c|}
\hline & \multicolumn{6}{|c|}{ Components } \\
\hline & $\begin{array}{l}\text { Purchase } \\
\text { policies }\end{array}$ & $\begin{array}{l}\text { Coordination } \\
\text { policies }\end{array}$ & $\begin{array}{l}\text { Payment } \\
\text { policies }\end{array}$ & $\begin{array}{l}\text { Corporate } \\
\text { image }\end{array}$ & $\begin{array}{l}\text { Delivery accord- } \\
\text { ing to TQM }\end{array}$ & $\begin{array}{l}\text { Supplier } \\
\text { satisfac- } \\
\text { tion }\end{array}$ \\
\hline PURCH1 & 0.72 & & & & & \\
\hline PURCH2 & 0.76 & & & & & \\
\hline PURCH3 & 0.7 & & & & & \\
\hline PURCH4 & 0.67 & & & & & \\
\hline PURCH5 & 0.67 & & & & & \\
\hline PURCH6 & 0.7 & & & & & \\
\hline COORD1 & & 0.68 & & & & \\
\hline COORD2 & & 0.79 & & & & \\
\hline COORD3 & & 0.77 & & & & \\
\hline COORD4 & & 0.65 & & & & \\
\hline COORD5 & & 0.61 & & & & \\
\hline COORD6 & & 0.66 & & & & \\
\hline Pay1 & & & 0.84 & & & \\
\hline Pay2 & & & 0.77 & & & \\
\hline Pay3 & & & 0.5 & & & \\
\hline Pay4 & & & 0.53 & & & \\
\hline COR1 & & & & 0.72 & & \\
\hline COR2 & & & & 0.6 & & \\
\hline COR3 & & & & 0.65 & & \\
\hline COR4 & & & & 0.5 & & \\
\hline COR5 & & & & 0.67 & & \\
\hline TQM1 & & & & & 0.63 & \\
\hline TQM2 & & & & & 0.81 & \\
\hline TQM3 & & & & & 0.77 & \\
\hline TQM4 & & & & & 0.87 & \\
\hline TQM5 & & & & & 0.81 & \\
\hline Satis 1 & & & & & & 0.73 \\
\hline Satis2 & & & & & & 0.8 \\
\hline Satis3 & & & & & & 0.74 \\
\hline Satis4 & & & & & & 0.67 \\
\hline Satis5 & & & & & & 0.79 \\
\hline
\end{tabular}


Table 2 PLS model and the measures of validity

\begin{tabular}{lllll}
\hline & Cronbach's alpha & rho_A & $\begin{array}{l}\text { Composite reli- } \\
\text { ability }\end{array}$ & $\begin{array}{l}\text { Average variance } \\
\text { extracted (AVE) }\end{array}$ \\
\hline Before reviewing the model in PLS & & & \\
Coordination policy & 0.914 & 0.919 & 0.914 & 0.642 \\
Corporate image & 0.87 & 0.878 & 0.973 & 0.581 \\
Payment policy & 0.881 & 0.896 & 0.881 & 0.653 \\
Purchase policy & 0.908 & 0.917 & 0.909 & 0.628 \\
Quality G\&S & 0.903 & 0.906 & 0.904 & 0.654 \\
Supplier satisfaction & 0.907 & 0.908 & 0.907 & 0.662 \\
After reviewing the model & & & & \\
Coordination policy & 0.828 & 0.828 & 0.828 & 0.706 \\
Corporate image & 0.735 & 0.74 & 0.737 & 0.484 \\
Payment policy & 0.809 & 0.823 & 0.814 & 0.688 \\
Purchase policy & 0.889 & 0.895 & 0.89 & 0.67 \\
Quality G\&S & 0.903 & 0.907 & 0.904 & 0.655 \\
Supplier satisfaction & 0.907 & 0.908 & 0.907 & 0.662 \\
\hline
\end{tabular}

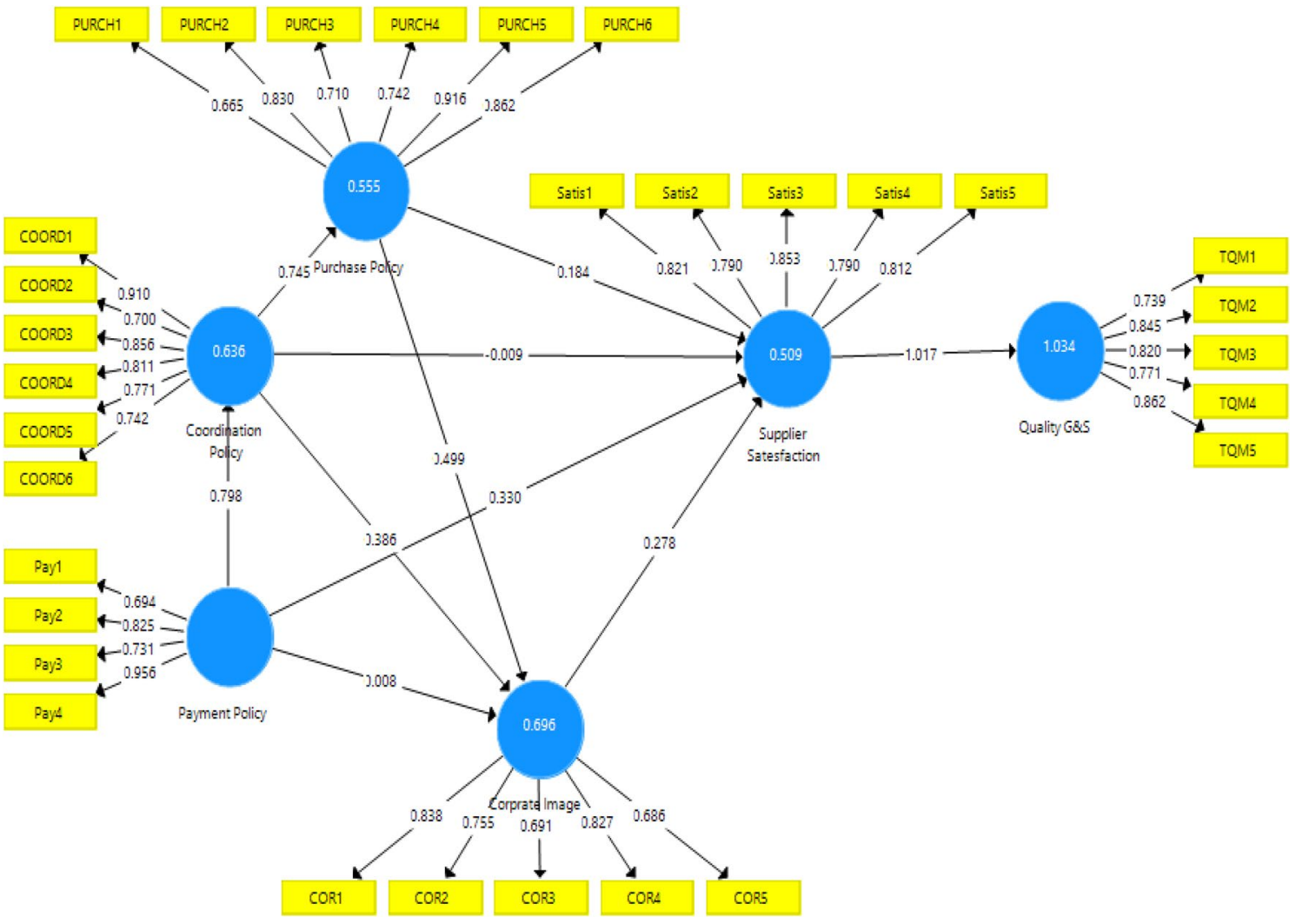

Fig. 8 Initial PLS-SEM model

TQM model. The effect of payment policy was considerably less on the corporate image, whereas it had a considerable effect on coordination policy [8]. Coordination policy had a little direct effect on supplier satisfaction, but a high effect on purchase policy. The supplier satisfaction had a very high impact on the quality variable, and hence, it was working as an intermediate variable. The coefficient of determination for the variables was considered high and greater than 0.5, which explained the variances of the factors of the EFA. The standardized root-mean-square residual (SRMR) for the saturated model was almost equal to 0.08 , signified that the initial model was not a good fit. The SRMR for the estimated 
model was even higher. The likelihood estimate was calculated as $\chi^{2}=1096.37$ and $\chi^{2}=1097.57$ for saturated and estimated models (Table 3 ).

The specific norm of Fornell-Larcker was cross-checked by the discriminating authenticity of the underlying variables. The diagonal values (square root of the AVE) were greater than the other values in the respective columns, establishing discriminant validity of the model (Table 4).

The multicollinearity of the PLS model was assessed from the VIF statistics, and the existence of multicollinearity was evident from the VIF statistics, as some of the values were distantly greater than 4.0. Underneath table represents the VIF statistics of the latent factors of the initial model (Table 5).

\section{Modified PLS-SEM model}

The final model (Fig. 9) was modified due to the high SRMR value in the initial PLS-SEM model. Bootstrapping was performed for the modification of the model, and the latent factors with loading less than 0.6 were excluded from the model. The new model improved the effect values, and negative impact factors were visible in the PLS network. The SRMR value for the saturated model was below 0.8 , and maximum-likelihood values (Chi-square) defined the validity (Table 6).

The multiple inter-correlative effects were eliminated through bootstrapping. On the other hand, the coefficients

Table 3 Initial model estimates for PLS-SEM

\begin{tabular}{lcc}
\hline & Saturated model & Estimated model \\
\hline SRMR & 0.081 & 0.087 \\
d_ULS & 3.258 & 3.735 \\
d_G1 & 4.581 & 4.713 \\
d_G2 & 3.744 & 3.865 \\
Chi-square & 1096.37 & 1097.57 \\
NFI & 0.597 & 0.597 \\
\hline
\end{tabular}

of variance inflation factor were reduced to somewhat less than 4.0. It, in turn, depicted that the limit of the tolerance criteria was lower than 0.25 and the regression module with the determining factors was quite important [6].

The criterion of Fornell-Larcker was cross-verified alongside the discriminant legitimacy of the underlying variables, and the integrity of fit impounded the discriminant authority of the model [3] (Table 7)

\section{Results of Hypothesis Testing}

The results of the PLS-PM analyses exhibited concerning values for the hypothesis testing [1]. The analyses revealed that purchase policy had a positive impact on supplier commitment (H1: $\beta=0.39, p<0.05)$. Purchasing policy had positive impact on corporate image (H2: $\beta=0.42$, $p<0.05)$. Financial policies indeed have a positive impact on supplier satisfaction (H3: $\beta=0.13, p<0.05)$. Payment policies appeared to be had significant impact $(\mathrm{H} 4: \beta=0.33$, $p<0.05)$ on corporate image. Payment policies appeared to be had significant positive impact (H5: $\beta=0.73, p<0.05$ ) on coordination policies. Coordination policies have positive effect on satisfied supplier commitment (H6: $\beta=0.15$, $p<0.05$ ). Coordination policies have positive effect on purchase policies (H7: $\beta=0.73, \mathrm{p}<0.05)$. However, coordination policies failed to have positive effect on corporate image (H8: $\beta=0.09, p>0.05$ ). Corporate image of the company had positive impact on supplier obligations (H9: $\beta=0.35$, $p<0.05$ ). Supplier obligation also acted as a mediating variable and had a positive impact on the delivery of goods and services. Also, the overall explanatory variables explained the variance in the model and the adjusted R-square values were almost equal to the coefficient of determinations (Tables 8, 9, 10, 11).

\section{Discussion}

The sole purpose of the study was to evaluate the preceding investigations and modify the end results of satisfaction of

Table 4 Fornell-Larcker criterion establishing discriminant validity

\begin{tabular}{|c|c|c|c|c|c|c|}
\hline \multicolumn{7}{|c|}{ Fornell-Larcker criterion } \\
\hline & $\begin{array}{l}\text { Coordination } \\
\text { policy }\end{array}$ & Corporate image & Payment policy & Purchase policy & Quality G\&S & $\begin{array}{l}\text { Supplier } \\
\text { satisfac- } \\
\text { tion }\end{array}$ \\
\hline Coordination policy & 0.838 & & & & & \\
\hline Corporate image & 0.681 & 0.814 & & & & \\
\hline Payment policy & 0.723 & 0.615 & 0.859 & & & \\
\hline Purchase policy & 0.687 & 0.714 & 0.686 & 0.829 & & \\
\hline Quality G\&S & 0.524 & 0.53 & 0.529 & 0.515 & 0.85 & \\
\hline Supplier satisfaction & 0.55 & 0.581 & 0.589 & 0.588 & 0.924 & 0.854 \\
\hline
\end{tabular}




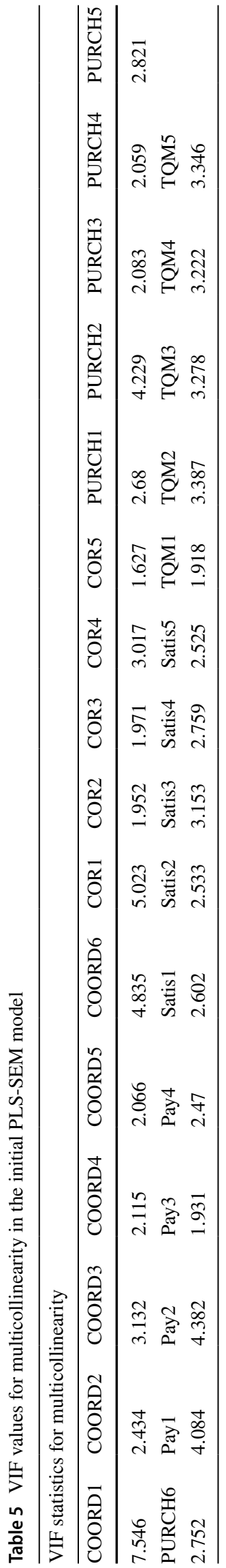

suppliers as an underlying impact variable on the quality of delivery. The discoveries demonstrated that purchase and imbursement procedures, alongside the corporate image, were significant forerunners of provider fulfilment and satisfaction. The outcomes were in sequence with earlier literature [8]. Here, the satisfaction of the suppliers effectively repeated the effect of the independent factors on the delivery of goods and service of the suppliers. Moreover, the outcomes strengthen the theory that the benefit of the relationship of four explanatory factors with the mediating cause could be an important expansion to the preliminary model. Shockingly, the deficiency of constructive consequence of well-though-out coordination policies on the corporate image was significant. This particular verdict was quite surprising, as the positive coordination policy had already affected the image of the suppliers. As a believable explanation, between associated forerunners and the assessable impacts of the purveyors' approval on provider fulfilment, this examination established the renovated model of the fulfilment of suppliers [7]. The hypothetical module clarified that some of the particular predecessors might affect the other factors, which, in turn, can propose the overhauled depiction and provide a clearer notion among social and financial factors. A two-way suggestion was quite evident in this aspect. These were the circuitous effect of the autonomous factors on the supplier quality, and the direct co-relation of the service as per the TQM model and the satisfaction of the supplier for upholding the prime delivery quality (Hüttinger, Schiele\& Schröer, 2014).

\section{Conclusion}

Businesses post-COVID-19 times need to respond to multiple fronts at the same time. The COVID-19 pandemic with a series of lockdown in India has manifested tremendous impacts on suppliers of products and services. Businesses need to work to protect the operational viability to combat supply-chain shocks. Many businesses are adopting crisismanagement mechanisms for building resilience for the future. The above model is one of the ways to ensure that supplier satisfaction is maintained and that the final quality of goods and services are not impacted. Adopting this model in determining factors that impact supplier satisfaction can enable businesses to improve their relationships with their suppliers. This model also enables create transparency on supply chains by determining critical components of suppliers.

\section{Future Implication}

This study is of interest to SMEs who are interested in improving business relationships with their suppliers. The research will also support the strengthening of cooperation with B2B partners to achieve a win-win situation. 


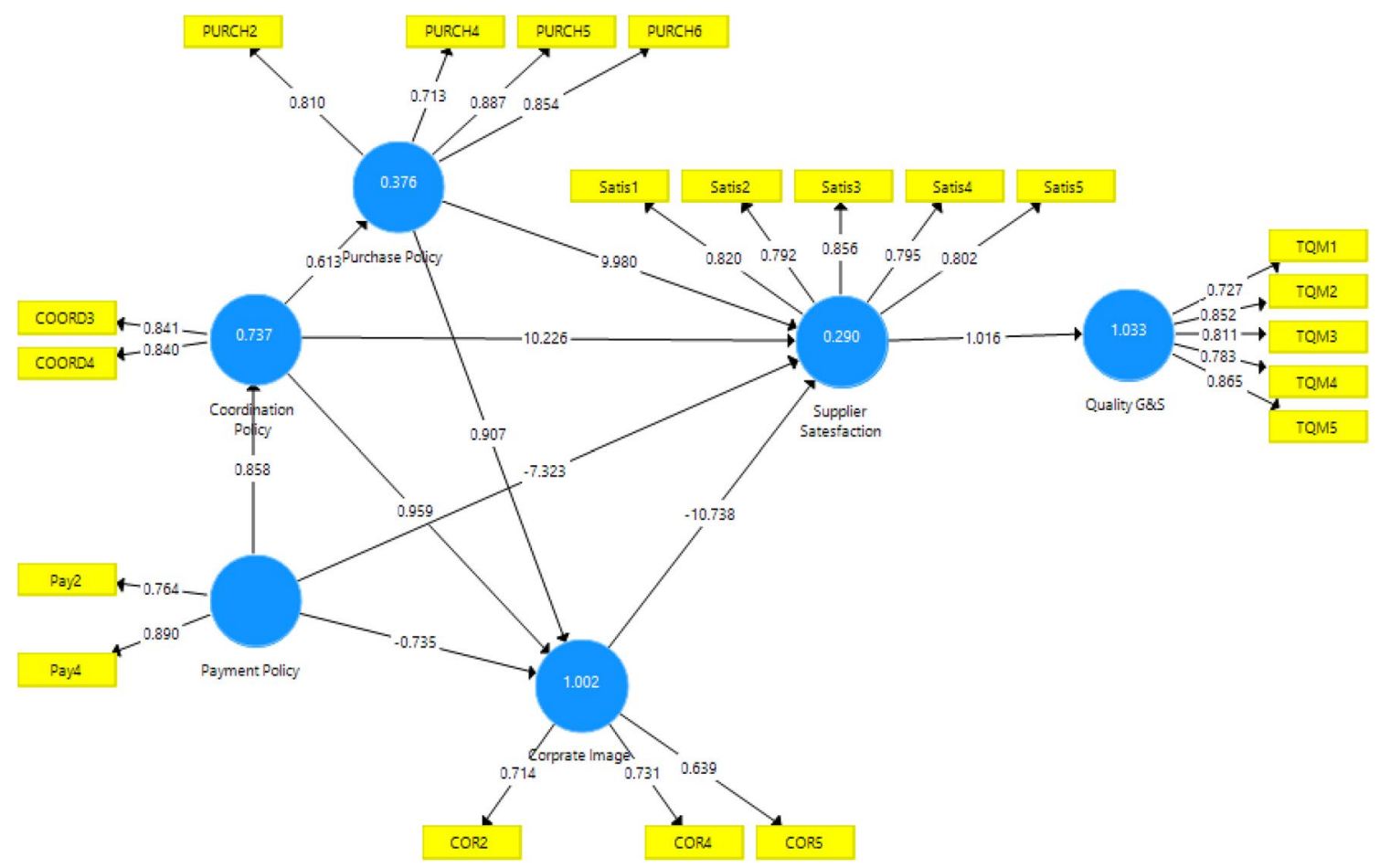

Fig. 9 Final PLS-SEM model for the goodness of fit

Table 6 Final model estimates for PLS-SEM

\begin{tabular}{lcc}
\hline & Saturated model & Estimated model \\
\hline SRMR & 0.068 & 0.106 \\
d_ULS & 1.058 & 2.599 \\
d_G1 & 1.628 & 1.967 \\
d_G2 & 1.485 & 1.759 \\
Chi-square & 460.18 & 528.699 \\
NFI & 0.704 & 0.66 \\
\hline
\end{tabular}

Table 7 VIF standards for multicollinearity in the concluding PLSSEM model

\begin{tabular}{llll}
\hline VIF statistics for multicollinearity & & \\
\hline COORD3 & 1.995 & Satis1 & 2.602 \\
COORD4 & 1.995 & Satis2 & 2.533 \\
COR2 & 1.439 & Satis3 & 3.153 \\
COR4 & 1.635 & Satis4 & 2.759 \\
COR5 & 1.397 & Satis5 & 2.525 \\
PURCH2 & 2.901 & TQM1 & 1.918 \\
PURCH4 & 1.889 & TQM2 & 3.387 \\
PURCH5 & 2.52 & TQM3 & 3.278 \\
PURCH6 & 2.52 & TQM4 & 3.222 \\
Pay2 & 1.859 & TQM5 & 3.346 \\
Pay4 & 1.859 & & \\
\hline
\end{tabular}


Table 8 The criterion of Fornell-Larcker for discriminant validity

Fornell-Larcker criterion

\begin{tabular}{|c|c|c|c|c|}
\hline $\begin{array}{l}\text { Coordination } \\
\text { policy }\end{array}$ & Corporate image & Payment policy & Purchase policy & Quality G\&S \\
\hline
\end{tabular}

Coordination policy $\quad 0.84$

Corporate image $\quad 0.884$

Payment policy $\quad 0.858$

Purchase policy $\quad 0.613$

Quality G\&S $\quad 0.59$

0.696

$\begin{array}{lll}0.858 & 0.861 & 0.829\end{array}$

$0.613-0.868$

$\begin{array}{lll}0.59 & 0.605 & 0.636\end{array}$

0.818

Supplier satisfaction $\quad 0.568$

0.662

0.716

0.592

0.809

$0.685 \quad 1.016$

0.814

Table 9 Indirect effect of the PLS-SEM model for the modified model

\begin{tabular}{|c|c|c|c|c|c|c|}
\hline \multicolumn{7}{|l|}{ Indirect effect } \\
\hline & $\begin{array}{l}\text { Coordination } \\
\text { policy }\end{array}$ & Corporate image & Payment policy & Purchase policy & Quality G\&S & Supplier satisfaction \\
\hline Coordination policy & & 0.556 & & & 0.084 & -10.143 \\
\hline Corporate image & & & & & -10.911 & \\
\hline Payment policy & & 1.3 & & 0.526 & 0.646 & 7.959 \\
\hline Purchase policy & & & & & 0.249 & -9.736 \\
\hline \multicolumn{7}{|l|}{ Quality G\&S } \\
\hline Supplier satisfaction & & & & & & \\
\hline
\end{tabular}

Table 10 Hypothesis testing decisions with path coefficients

\begin{tabular}{|c|c|c|c|}
\hline $\begin{array}{l}\text { Hypotheses ( } \beta \text { coef- } \\
\text { ficients) }\end{array}$ & Path & Path coefficient & Decision \\
\hline H1 & $\mathrm{PURCH} \longrightarrow \mathrm{SS}$ & $0.389 * * * *$ & Supported \\
\hline $\mathrm{H} 2$ & $\mathrm{PURCH} \longrightarrow \mathrm{CORPO}$ & $0.416 * * *$ & Supported \\
\hline H3 & $\mathrm{PAY} \longrightarrow \mathrm{SS}$ & $0.126^{*}$ & Supported \\
\hline H4 & $\mathrm{PAY} \longrightarrow \mathrm{CORPO}$ & $0.326^{* *}$ & Supported \\
\hline H5 & $\mathrm{PAY} \longrightarrow \mathrm{COORDO}$ & $0.730 * * * *$ & Supported \\
\hline H6 & $\mathrm{COORD} \longrightarrow \mathrm{SS}$ & $0.150 *$ & Supported \\
\hline H7 & $\mathrm{COORD} \longrightarrow \mathrm{PURCH}$ & $0.726 * * * *$ & Supported \\
\hline H8 & $\mathrm{COORD} \longrightarrow>\mathrm{CORPO}$ & 0.089 & Not supported \\
\hline H9 & $\mathrm{CORPO} \longrightarrow \mathrm{SS}$ & $0.346 * * * *$ & Supported \\
\hline
\end{tabular}

Notes: Significant at: $* p<0.01,{ }^{*} p<0.0013, * * * p<0.0002, * * * * p<0.0001$
Table 11 Model variance explanation with R-square values

\begin{tabular}{lll}
\hline & R-square & R-square adjusted \\
\hline Coordination policy & 0.737 & 0.733 \\
Corporate image & 1.002 & 1.002 \\
Purchase policy & 0.376 & 0.367 \\
Quality G\&S & 1.033 & 1.033 \\
Supplier satisfaction & 0.29 & 0.249 \\
\hline
\end{tabular}

Funding Not applicable.

Availability of Data and Materials Yes.

Code Availability Yes.

\section{Declarations}

Conflict of Interest The authors declare that they have no conflict of interest. 
Ethics Approval Not applicable.

Consent to Participate Not applicable.

\section{Consent for Publication Yes.}

\section{References}

1. Abdi H, Williams LJ. Principal component analysis. Wiley Interdisciplin Rev. 2010;2(4):433-59.

2. Ajzen I. The theory of planned behaviour: Reactions and reflections. Psychol Health. 2011;26(9):1113-1127. https://doi.org/10. 1080/08870446.2011.613995

3. Hult GTM, Hair JF Jr, Proksch D, Sarstedt M, Pinkwart A, Ringle $\mathrm{CM}$. Addressing endogeneity in international marketing applications of partial least squares structural equation modeling. J Int Mark. 2018;26(3):1-21.
4. Hair JF, Sarstedt M, Ringle CM, Mena JA. An assessment of the use of partial least squares structural equation modeling in marketing research. J Acad Mark Sci. 2012;40(3):414-33.

5. Hüttinger L, Schiele H, Schröer D. Exploring the antecedents of preferential customer treatment by suppliers: a mixed methods approach. Supply Chain Manag. 2014;19(5/6):697-721.

6. Lowry PB, Gaskin J. Partial least squares (PLS) structural equation modeling (SEM) for building and testing behavioral causal theory: When to choose it and how to use it. IEEE Trans Prof Commun. 2014;57(2):123-46.

7. Pulles NJ, Schiele H, Veldman J, Hüttinger L. The impact of customer attractiveness and supplier satisfaction on becoming a preferred customer. Ind Mark Manage. 2016;54:129-40.

8. Vos FG, Schiele H, Hüttinger L. Supplier satisfaction: Explanation and out-of-sample prediction. J Bus Res. 2016;69(10):4613-23.

Publisher's Note Springer Nature remains neutral with regard to jurisdictional claims in published maps and institutional affiliations. 